\title{
Repair Strategies in EFL Classroom Talk
}

\author{
Zahra Fotovatnia \\ English Department, Najafabad Branch, Islamic Azad University, Najafabad, Iran \\ Afrooz Dorri \\ English Department, Najafabad Branch, Islamic Azad University, Najafabad, Iran
}

\begin{abstract}
This study investigated the repair strategies employed by Iranian female and male intermediate EFL learners to find out if there were differences in the usage of repair strategies by class type (single-gender vs. mixed-gender) and the gender of the learners and the teacher. The participants of the study were 32 EFL learners (16 males and 16 females). At first, all of the learners were assigned to a mixed-gender class and the textbook was taught to them during 16 sessions (eight sessions with a male teacher and eight sessions with a female teacher). Then the learners were divided into two single-gender classes and teaching of the textbook continued for the two classes. All the sessions were video recorded. Then, the learners' repair strategies were analyzed through the study. The results revealed three important findings. First, single-classes used more repair strategies than mixed-classes. Second, there was no difference in using the repair strategies based on the gender of the learners, irrespective of the gender of the teacher. Third, there was no difference in using the repair strategies based on the gender of the teacher. The findings add new information to L2 research on repair strategies and, pedagogically speaking, the findings of the study have implications for EFL teachers and students.
\end{abstract}

Index Terms - conversational analysis, repair, repair strategies

\section{INTRODUCTION}

The number of students who are enrolling in English as a Foreign Language (EFL) classes continues to increase. Typically in EFL classes, the instruction is delivered in English, although many EFL students have limited English competence (Cho, 2008; van Lier, 1988). The students' limited competence can create miscommunication between the students and their teachers and the students themselves. In many situations, students try to solve these miscommunication problems between the teachers and other students to gain an appropriate understanding. Schegloff, Jefferson, and Sacks (1977) call these kinds of activities conversational repairs, which are defined as strategies used by students for resolving miscommunication problems involving speaking, hearing, and understanding. Therefore, repairs may be defined as the treatment of trouble occurring in interactive language use. Liebscher and Dailey-O'Cain (2003) define conversational repairs as the persistent behaviors that are observed immediately subsequent to the occurrence of a communication breakdown, defined as a situation in which the goal or intent of the behavior is not understood or is misunderstood by the communication partner and, therefore, is not followed by a desired outcome within a reasonable length of time. Understanding how students treat these communication breakdowns will provide teachers with more insights into how to develop lessons to assist students in the development of their language proficiency. It is proposed that if educators are aware of the types of conversation breakdowns and the employed repair strategies, they can utilize the necessary instructional strategies to assist students in the development of more sophisticated repair strategies (Cho \& Larke, 2010, p. 2).

From the previous researches, adult language learners employed nine types of repair strategies. Five of these adult language learners' repair strategies are from Schegloff et al. (1977), which include unspecified, interrogatives, (partial) repeat, partial repeat plus question word, and understanding check. Egbert (1998) provides one-request for repetitionand Liebscher and Dailey-O'Cain (2003) have another, request for definition, translation, or explanation. Cho (2008) adds 2 more-correction, and nonverbal strategies. Goodwin (2000) said that nonverbal resources have been included in that they affect the meaning making process. Participants in conversation use not only verbal resources but also nonverbal resources to accomplish their communication (Hayashi, 2003; Streeck, 2003 cited in Cho \& Larke, 2010, p. 8). These repair strategies are used for communication breakdown from their natural conversation to classroom conversation. Among these nine types of repair strategies-that are described below one by one - understanding checks are the most common repair types and requests for repetition are the least frequent one. Students do not use some repair types such as interrogatives and partial repeats with question words because those repairs require a combination of cognitive, linguistic and interactive skills that may not yet be highly developed. Students show a preference for more specific repair initiation techniques when interacting with the teacher (Cho \& Larke, 2010, p. 2). Students use this type "to avoid committing face-threatening acts that would seem inappropriate to their role in the classroom as learners". The following description of these nine types of repair strategies is based on Cho \& Larke (2010):

\section{Unspecified Repair Example}


This type of strategy does not specify what the trouble source is (e.g., huh? pardon? I'm sorry? etc.). This repair initiation usually yields a repetition of the trouble source, which the repair initiator could not hear or understand the meaning of on the previous turn.

An example of unspecified repair:

T: Alright, we get to read a book today. Have you been at a zoo?

S: $\underline{U h}$ ?

$\mathrm{T}:$ Have you been at the zoo?

S: ((shrug his shoulder))

T: You've been in the zoo?

S: Yes (p. 14)

\section{Interrogatives Repair Example}

This type of strategy starts with a single question word such as who, where or when as repair initiations. This type of strategy specifies trouble source of prior turn.

An example of interrogatives repair:

T: Let's see and we are gonna read a book. Have you read it before?

S: That's easy

T: Easy: I'm glad you all think easy. Ok start on the first page. This is Silvia. This is her papa. They are from Mexico or Spain.

S: Who?

T: Silvia. It is Spanish name. (p. 15)

3. Partial Repeat plus a Question Word Repair Example

This type includes repetition of the trouble source turn with a question word.

An example of partial repeat plus a question word repair:

$\mathrm{T}$ : Ok. On the paper where are the back paws (.) can you circle that for me? Back paws?

S 1: (pointing at the wrong word on the worksheet)

T: Right here, see that? Those are the back paws, they use like hands. See that? Right there. Ok, look at your little finger.

S 2: Where is back paw?

$\mathrm{T}$ : (pointing at the word 'paw' on the worksheet) right there

S 2: Back paw?

S: Uh huh

S 2: Back paw (p. 17)

4. Partial Repeat Repair Example

In repeats and partial repeats, some of the trouble source turn is used again in the repair initiation, which makes them more specific than unspecified repair initiations.

An example of Partial Repeat Repair:

$\mathrm{S}$ : Which means useless and hind?

T: Hind? Uhm, hind means the back

S: Back?

T: Uh Huh. And useless means that they don't have any work. They don't have any purpose. (p. 12)

\section{Understanding Check Repair Example}

This type of repair strategy provides an alternate for understanding the trouble source. The speaker targets the trouble source more specifically than other strategies. In providing an understanding, the speaker indicates his or her interpretation of the trouble source turn. This type also refers to the students' repair moves where they explicitly say, "I don't know" or "I don't understand" to show their understanding problems and initiate repair.

An example of Understanding Check Repair:

T: Everybody's gonna have surprise party, everybody has to be very quiet, the person is not gonna know. Opposite of quiet is what?

YEAH: everybody says happy birthday very noisy, noisy, loud. Noisy......quiet

S: Magic?

$\mathrm{T}:$ It's magic birthday I guess

$\mathrm{S}:$ Is it turning up?

T: Yes it is turning up. Ok. Everybody needs to be really really quiet, shh::: now want to be noisy? Can you be noisy? WOW AH:: those are opposite. Ok. (p. 11)

6. Request for Repetition Example

This type is similar to the unspecified category in that it can also yield a repetition of the trouble source turn as response.

An example of Request for Repetition:

T: Ok. Today I sneeze wobbly. Yesterday I, what verb form?

$\mathrm{S}$ 1: Uhm? One more time 
T: Today I sneeze wobbly

S 2: Sneezed

$\mathrm{T}$ : Yeah sneezed.

S 1: Aha (p. 17)

\section{Request for Definition Example}

Here the student initiates repair to the word which she needs translation. The teacher provides the definition of the word.

An example of Request for Definition:

T: There you go. You wanna read this?

S: Male seals and sea lions are called bulls, females are called cows, their babies are called pups, the pups are usually born on land.

S: Um, what is female and pups?

T: Females and pups?

S: Yeah

T: Females are girls

S: Aha

T: Yeah male seals, boy seals, are called bulls like big cow female seals are called cows, this is a little baby called pup. (p. 16)

8. Nonverbal Resources Repair Example

This category of nonverbal strategies includes students' gesture, bodily movement, gaze, facial expression and silence.

An example of Nonverbal Resources Repair:

$\mathrm{T}$ : What day of the week tomorrow?

S: (patting his hand with making squint eyes)

$\mathrm{T}$ : What's tomorrow? It starts with $\mathrm{f}$

S: Friday

T: See? You know that. (p. 15)

9. Correction Repair Example

The students tended to use this strategy explicitly in their classroom conversation. Correction is related to not only linguistic errors but also comprehension of the trouble source turn.

An example of Correction Repair:

$\mathrm{T}$ : What's the opposite of new? You are wearing new shoes.

S 1: I got new shoes too.

$\mathrm{T}$ : These shoes are not new. They are what?

S 2: (gazing at the teacher)

S 1: $\underline{\text { Old }}$

T: Old. New and old. Those are opposites. (p. 16)

Based on the above literature, the following research questions were addressed in this study:

1. Does the use of repair strategies differ according to class type (single-gender vs. Mixed-gender)?

2. Does the use of repair strategies differ according to the gender of the EFL learners?

3. Does the use of repair strategies differ according to the gender of the teacher?

\section{MEthodology}

\section{Participants}

The participants were female and male intermediate EFL learners of Kooshesh Institute in Najafabad, Iran, native speakers of Persian, ranging in age from 15 to 20 and studying English as the second language and selected based on their English proficiency scores. They took an Oxford Placement Test [OPT, Allan, 2004]. Thirty-two participants (16 males and 16 females), whose scores were between one standard deviation above and below the mean were selected for the subsequent stages of the study. They were studying Interchange 1(2005).

\section{Materials}

Three kinds of materials containing OPT, video records of 48 sessions of teaching, and transcriptions of the video recorded sessions were used in the study:

A. Oxford Placement Test (OPT): this test was developed by Dave Allen (2004). This is a 50-item multiple-choice test that homogenizes the participants in terms of English proficiency level; it contains 25 grammar items and 25 vocabulary items and took 40 minutes to administer.

B. Video records of 48 sessions of teaching: the video records were prepared in 48 sessions, when the textbook was taught to the participants. All the interactions between the teachers and the learners and among the learners themselves were video recorded. 
C. Transcriptions of the video recorded sessions: each video recorded session was transcribed in order to extract the repair strategies used by the participants based on 9 types of repair strategies taken from Schegloff et al. (1995), Egbert (1998), Liebscher and Dailey-O'Cain (2003), Cho (2008), as described in Introduction.

To determine each strategy, two coders were used. Every one transcribed each session and extracted the repair strategies used in that session. When there was an agreement between the coders, the strategy was given a label. However, when there was no agreement between the coders regarding the label given to the strategy, a third coder was consulted.

\section{Procedures}

At first, 16 male and 16 female participants in a mixed-gender class were taught by the male teacher in eight sessions. After that the mixed-gender class that consisted of 32 learners was taught by the female teacher in eight sessions. Then the mixed-gender class containing 16 male and 16 female participants was divided into two single-gender classes: one class contained 16 male participants and the other contained 16 female participants. The male single-class containing 16 male participants was taught by the male teacher in eight sessions and then by the female teacher in eight sessions. These male and female teachers were those who taught the mixed-gender class.

The female single-class containing 16 female participants was taught by the male teacher in eight sessions and then by the female teacher in eight sessions. These male and female teachers were those who taught the mixed-gender class and the male single-class too.

Figure 3.1 represents the summary of these steps:

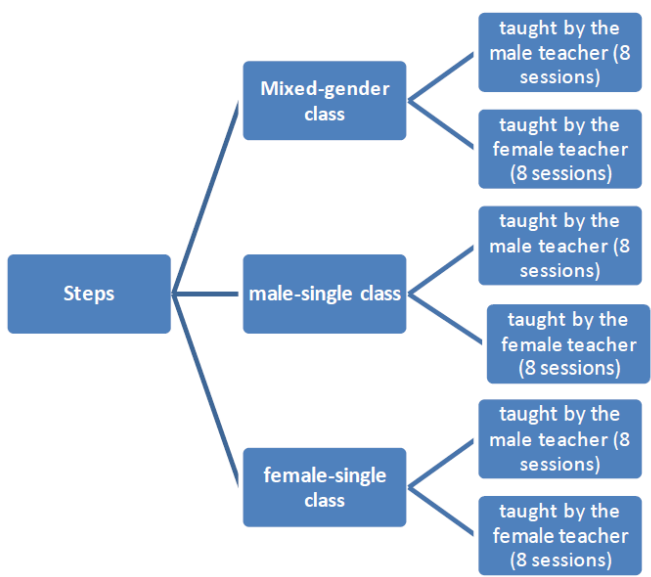

Figure 1: the steps of data collection in the mixed-gender class, the male single-class and the female single-class

\section{DATA ANALYSIS}

To analyze the data, one point was given to each strategy used by the participants and zero point to those unused strategies. Then all numbers were added together and the comparison was started. The researchers used the Statistical Package for Social Sciences (SPSS, Version 16) to answer the research question.

\section{RESULTS}

\section{Repair strategies according to class type (single-gender vs. mixed-gender)}

In order to see if the differences were statistically significant, first a test of homogeneity of variances was run. Table 1 shows the results.

TABLE 1

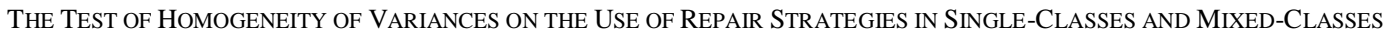

Test of Homogeneity of Variances

\begin{tabular}{|c|c|c|c|}
\hline $\begin{array}{l}\text { Levene } \\
\text { Statistic }\end{array}$ & df1 & $\mathrm{df} 2$ & Sig. \\
\hline 10.873 & 5 & 1146 & .000 \\
\hline
\end{tabular}

Table 1 indicates that the level of significance is less than .05. Thus variances of the means are not equal. After the homogeneity test, a planned comparison one-way ANOVA was run. Table 2 shows the results. So in the contrast tests table, we use the level of significant and the $t$ index in the second row (does not assume equal). 
TABLE 2

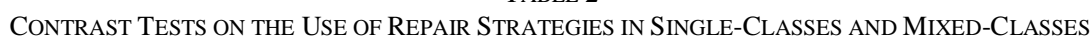

\begin{tabular}{|lll|r|r|r|r|r|}
\hline \multicolumn{1}{|c|}{ Contrast Tests } \\
\hline & & Contrast & $\begin{array}{c}\text { Value of } \\
\text { Contrast }\end{array}$ & Std. Error & $\mathrm{t}$ & \multicolumn{1}{c|}{ df } & Sig. (2-tailed) \\
\hline \multirow{2}{*}{ strategy } & Assume equal variances & 1 & -.8542 & .19823 & -4.309 & 1146 & .000 \\
\cline { 2 - 9 } & Does not assume equal & 1 & -.8542 & .19827 & -4.308 & 998.334 & .000 \\
\hline
\end{tabular}

The results of the planned comparison test is displayed in Table 4.5: $F(5,1146)=18.55, p=.000$. Then the difference between the use of repair strategies in single-classes and mixed-classes is significant and according to the mean plots, single classes used more strategies.

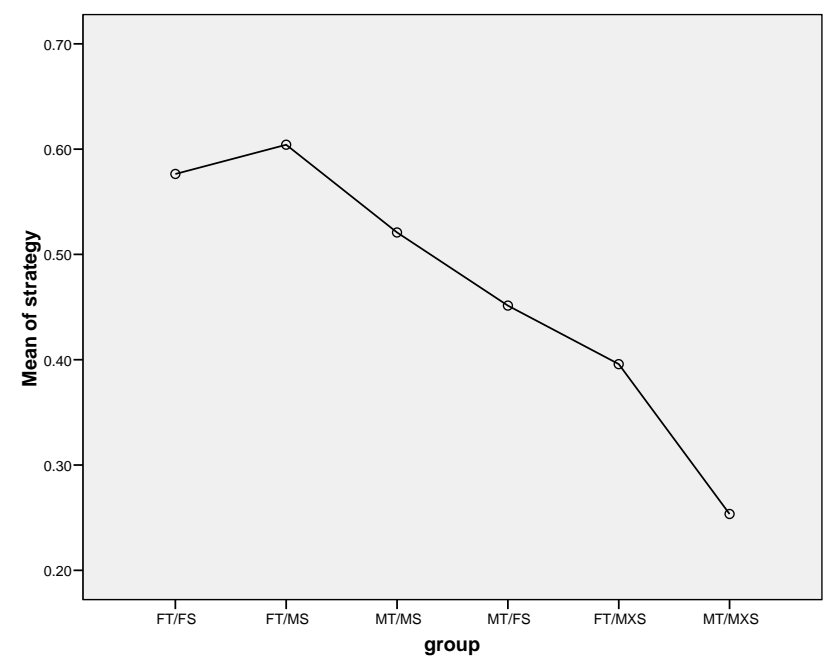

Figure 2: means plots

\section{Repair strategies according to the gender of the participants}

In order to see if the differences were statistically significant, first a test of homogeneity of variances was run. Table 3 shows the results.

TABLE 3.

THE TEST OF HOMOGENEITY OF VARIANCES ON THE USE OF REPAIR STRATEGIES BASED ON THE GENDER OF THE PARTICIPANTS

Test of Homogeneity of Variances

strategy
\begin{tabular}{rl|l|l|l|}
\hline $\begin{array}{l}\text { Levene } \\
\text { Statistic }\end{array}$ & df1 & df2 & Sig. \\
\hline 10.873 & 5 & 1146 & .000 \\
\hline
\end{tabular}

Table 3 indicates that the level of significance is less than .05. Thus variances of the means are not equal. After the homogeneity test, a planned comparison one-way ANOVA was run. Table 4 shows the results. So in the contrast tests table, we use the level of significant and the $t$ index in the second row (does not assume equal).

TABLE 4.

CONTRAST TESTS ON THE USE OF REPAIR STRATEGIES BASED ON THE GENDER OF THE PARTICIPANTS

Contrast Tests

\begin{tabular}{|lll|r|r|r|r|r|}
\hline & & Contrast & $\begin{array}{l}\text { Value of } \\
\text { Contrast }\end{array}$ & \multicolumn{1}{c|}{ Std. Error } & \multicolumn{1}{c|}{$\mathrm{t}$} & \multicolumn{1}{c|}{ df } & Sig. (2-tailed) \\
\hline \multirow{2}{*}{ strategy } & Assume equal variances & 1 & .0972 & .14017 & .694 & 1146 & .488 \\
\cline { 2 - 8 } & Does not assume equal & 1 & .0972 & .15445 & .629 & 558.557 & .529 \\
\hline
\end{tabular}

The results of the planned comparison test is displayed in Table 4: $F(5,1146)=.39, p=.529$. Then the difference between the performances of participants on the use of repair strategies is not significant. It means there was no difference in using the repair strategies between females and males in general, irrespective of the gender of the teacher.

\section{Repair strategies according to the gender of the teacher}

In order to see if the differences were statistically significant, first a test of homogeneity of variances was run. Table 5 shows the results. 
TABLE 5.

THE TEST OF HOMOGENEITY OF VARIANCES ON THE USE OF REPAIR STRATEGIES BASED ON THE GENDER OF THE TEACHER

Test of Homogeneity of Variances

\begin{tabular}{|c|c|c|c|}
\hline $\begin{array}{l}\text { Levene } \\
\text { Statistic }\end{array}$ & df1 & $d f 2$ & Sig. \\
\hline 10.873 & 5 & 1146 & .000 \\
\hline
\end{tabular}

Table 5 indicates that the level of significance is less than .05 . Thus variances of the means are not equal. After the homogeneity test, a planned comparison one-way ANOVA was run. Table 6 shows the results. So in the contrast tests table, we use the level of significant and the $t$ index in the second row (does not assume equal).

TABLE 6.

CONTRAST TESTS ON THE USE OF REPAIR STRATEGIES BASED ON THE GENDER OF THE TEACHER

\begin{tabular}{|lll|r|r|r|r|r|}
\multicolumn{1}{|c|}{ Contrast Tests } \\
\hline & Contrast & $\begin{array}{c}\text { Value of } \\
\text { Contrast }\end{array}$ & Std. Error & $\mathrm{t}$ & \multicolumn{1}{c|}{ df } & Sig. (2-tailed) \\
\hline \multirow{2}{*}{ strategy } & Assume equal variances & 1 & -.2083 & .14017 & -1.486 & 1146 & .137 \\
\cline { 2 - 10 } & Does not assume equal & 1 & -.2083 & .15445 & -1.349 & 558.557 & .178 \\
\hline
\end{tabular}

The results of the planned comparison test is displayed in Table 4.11: $F(5,1146)=1.81, p=.178$. Then the difference between the performances of participants on the use of repair strategies is not significant. It means there was no difference in using the repair strategies based on the gender of the teacher.

\section{DisCUSSION AND CONCLUSION}

The study was intended to analyze the differences of Iranian students' use of repair strategies in single and mixed class. It showed that the participants used more strategies in single-gender class than mixed-gender class. In addition, the study was aimed to determine the influence of the gender of the teacher and the learners on the use of repair strategies. As it was illuminated in the preceding section of the study, the findings of the study reveal that:

First, the participants used more strategies in single-gender class than mixed-gender class.

Second, no relationship between the gender of students and the use of repair strategies was found. In other words, there was no difference in using the repair strategies between females and males in general, irrespective of the gender of the teacher.

Third, based upon the findings of the study, there were no significant differences between the performances of the learners on the use of repair strategies when the gender of the teacher was a variable. In other words, no significant differences were observed when the students and the teacher were of the same or different gender.

Jim Duffy, Kelly Warren, Margaret Walsh (2002) suggested that some boys and some girls feel more comfortable and more motivated in single-sex classes, and that academic achievement can be enhanced. Then, there has been a renewed push for single-sex education. Riordan (2002) said that there has been a resurgence of interest in single sex schools in modern societies across the globe, both in the public and private sector. Single gender classes provide students with another type of learning style that may be beneficial to them. Gray and Wilson (2006) argued that some parents do not want their children to be in mixed-gender classrooms because, especially at certain ages, students of the opposite sex can be a distraction. Also, single-sex education enhances student success when teachers use techniques geared toward the gender of their students. For example, girls learn better when classroom temperature is warm, while boys perform better in cooler classrooms. If that is true, then the temperature in a single-sex classroom could be set to optimize the learning of either male or female students.

The results of Billger's study (2009) indicated that there are three reasons for choosing a single sex school:

1. Let them be themselves: Boys tend to soften their competitive edge and become more collaborative in a single sex setting. They can just be boys and not worry about what the girls might think. Boys enjoying poetry and playing in an orchestra as opposed to a marching band are the kind of thing you will see in a boys' school. Girls drop their shyness and begin to take risks in a single sex setting. They become more competitive. They embrace sports like field hockey and soccer with gusto without worrying about appearing like boys.

2. Academics: If the teacher understands how to teach girls, they will quickly feel comfortable exploring nontraditional subjects such as mathematics, advanced sciences, computers and technology, wood-working and so on. Boys participate in choirs and orchestras and learn Latin in single sex settings. Children will break out of their stereotypical roles and behavior when they are left to their own devices. Single sex education has a delightful way of encouraging children to be fearless, to be curious, to be enthusiastic - in short, to just be themselves.

3. Socialization: Children are subjected to an avalanche of pressures from every quarter to become adults before they are ready to do so. They grow up too quickly. Why not let them be children for a few more years? Single sex education with its gentler, more controlled social outlets is just the ticket for many children. 
The same thing is true about the classrooms in Iran: When working with students raised in a culture where strict gender roles are the norm, and boys and girls are not normally allowed to socialize with one another, students performed considerably better when segregated by sex. Negative gender roles are often sharpened in coeducational environments. When boys and girls sit next to each other in class, it is easy to get distracted. When girls have boys in the class, girls do not feel comfortable saying things because they are scared of answering the question wrong. Girls and boys are motivated differently, and separating them helps them reach their full potential. For instance, when a teacher asks a question in a mixed-gender class, boys raise their hand in the air while a girl raises it to her shoulder. The girl might know much more than the boys but she is more shy. The boys speak with no idea what they are talking about. In an all-girls class, girls are encouraged to speak up without inhibition. It seems that young girls are more willing to ask and answer questions in classrooms without boys and young boys in classrooms without girls.

\section{IMPLICATIONS OF THE STUDY}

Implications of the current study are presented in three respects:

- This study raises the need for EFL teachers and researchers to be aware of factors that affect the use of repair strategies, for example, if the gender of the teacher or the students influences on the use of the repair strategies.

- Teachers will be able to respond to the communication problems of students more effectively when they understand the students' ways of resolving the conversation problems and the factors that affect them.

- Instead of analyzing linguistic products of students, this study also focused on the processes toward mutual understanding between students and teachers.

The present study suffered from several limitations such as small sample of participants and limitations of fund and time. Also, this study explored only intermediate level of proficiency; therefore, it hinders generalization of the findings to a broader range of proficiency levels.

\section{REFERENCES}

[1] Allan, P. (2004). Oxford placement test. Oxford University Press.

[2] Billger, M. (2009). Reconstructing School Segregation: On the Efficacy and Equity of Single-Sex Schooling. Economics of Education Review, 28, 398-403.

[3] Cho, E. (2008). An examination of the use of repair strategies of elementary English as a second language (ESL) students. Unpublished doctoral dissertation. Texas A \& M University, College Station.

[4] Cho, E. \& Larke, P. (2010). Repair Strategies Usage of Primary Elementary ESL Students: Implications for ESL Teachers. Journal for English as a Second Language, 14 (3).

[5] Duffy, J., Warren, K. and Walsh, M. (2002). Classroom interactions: gender of teacher, gender of student, and classroom subject. Sex roles, 45 (9/10), 579-593.

[6] Egbert, M. M. (1998). Miscommunication in language proficiency interviews of first-year German students: A comparison with natural conversation. In R. Young \& W. He. (Eds.), Talking and testing: Discourse approaches to the assessment of oral proficiency (pp. 147-169). Amsterdam, PA: John Benjamins Publishing Company.

[7] Goodwin, C. (2000). Action and embodiment within situated human interaction. Journal of Pragmatics, 32 (10), $1489-1522$.

[8] Gray, C., \& Wilson, J. (2006). Teachers' experiences of a single-sex initiative in a co-education school. Educational Studies, 32 (3), 285-298.

[9] Hayashi, M. (2003). Language and the body as resources for collaborative action: a study of word searches in Japanese conversation. Research on Language and Social Interaction, 26, 109-141.

[10] Liebscher, G. \& Dailey-O'cain, J. (2003). Conversation repair as a role defining mechanism in classroom interaction. The Modern Language Journal, 87 (iii), 375-390.

[11] Riordan, C. (2002). Girls and boys in school: Together or Separate? New York: Teacher's College Press.

[12] Schegloff, E. A., Jefferson, G. \& Sacks, H. (1977). The performance for self-correction in the organization of repair in conversation. Language, 53(ii), 361-382.

[13] Streeck, J. (2003). Interaction by inscription, Journal of Pragmatics, 33 (4), 465-490.

[14] Van Lier, L. (1988). The classroom and the language learner. New York: Longman Inc.

Zahra Fotovatnia is Assistant Professor of Applied Linguistics at Islamic Azad University, Najafabad Branch. She has been an instructor and a researcher for over 16 years. She has attended the following conferences: Metaphor Festival, Sweden, 2011; Second International Conference on Literature, language and Linguistics, Greece, 2009; EuroSLA 2007 UK; Asia TEFL, Malaysia; 8th International European conference of Psychology, Spain; and ICP2004 Beijing. She has published articles in Journal of Social Sciences and Humanities of Shiraz University, 23, 1, 2006; Language Forum, 32, 1-2, 2006; and Pajjohesh in Educational Sciences, 2, 4, 2004. Her area of interest includes pedagogical phonetics and phonology, psycholinguistics, and Teaching Methodology.

Afrooz Dorri holds an M.A. in TEFL from Islamic Azad University, Najaf Abad Branch. She is currently teaching English at high school. Her areas of interest include discourse analysis, sociolinguistics, and L2 methodology. 